\title{
Paraquat poisoning: Acute lung injury - a missed diagnosis
}

\author{
S D Ntshalintshali, MD (Cuba), MB ChB; T C Manzini, MB ChB, FCP (SA), Infect Dis Cert \\ Department of Internal Medicine, Ngwelezana Hospital, Empangeni, KwaZulu-Natal, South Africa
}

Corresponding author: S D Ntshalintshali (sipho.duncan@gmail.com)

\begin{abstract}
Paraquat is a herbicide of great toxicological importance because it is associated with high mortality rates, mainly due to respiratory failure. We report the case of a 28-year-old man admitted to the casualty department at Ngwelezana Hospital, Empangeni, KwaZuluNatal, South Africa, with a history of vomiting and abdominal pain after ingestion of $\sim 100 \mathrm{~mL}$ of an unknown substance, later identified as paraquat, together with an unknown amount of alcohol, in a suicide attempt. He developed respiratory distress associated with lung parenchymal infiltrates that required ventilatory support and later a spontaneous pneumothorax, and died in the intensive care unit. We discuss the importance of a high index of suspicion of paraquat poisoning in rural areas, where paraquat is readily available as a herbicide on farms, in patients with a similar presentation. We further stress the importance of identifying the classic radiological progression after paraquat poisoning, to help avoid a delay in diagnosis if the culprit substance is not known (as happened in our case). Lastly, we look at the importance of avoiding oxygen supplementation, and early administration of immunosuppressive therapy, to improve outcome.
\end{abstract}

S Afr Med J 2017;107(5):399-401. DOI:10.7196/SAMJ.2017.v107i5.12306

Paraquat poisoning is frequent in rural and agricultural regions around the world owing to the agricultural use of this compound as a herbicide. ${ }^{[1]}$ It is readily available in agricultural areas of South Africa (SA), as evident in the case described below. Making a timeous diagnosis and administering appropriate stepwise treatment is of paramount importance. In writing this article, we specifically hoped to raise awareness about the pulmonary manifestations and treatment of acute lung injury after paraquat ingestion.

\section{Case report}

In November 2016, a 28-year-old man presented to Ngwelezana Hospital, Empangeni, KwaZulu-Natal, SA, with a history of having attempted suicide $\sim 2$ hours earlier by ingesting $\sim 100 \mathrm{~mL}$ (half a cup) of herbicide after drinking an unknown amount of alcohol. On the 7th day after admission the herbicide was positively identified as paraquat when relatives brought an empty can to the hospital. $\mathrm{He}$ had no comorbid illnesses, but had experienced an episode of abdominal discomfort and vomiting on his way to the emergency department.

On examination, the patient appeared to have alcohol intoxication, with slurred speech, an ataxic gait and an ethanol smell. He was well hydrated and coherent to commands. He had no stigmata of any chronic illnesses. His vital signs, oxygen saturation, glucometer reading and urine dipstick test results were within normal limits. The rest of the examination was unremarkable.

On day 5 after admission to hospital, the patient developed multiple ulcerating bleeding lesions in his mouth and pharynx, and type 1 respiratory failure. At this point he was commenced on intravenous antibiotics and oxygen supplementation on the assumption that he had developed a nosocomial pneumonia. The respiratory failure worsened, and he was transferred to the intensive care unit (ICU) for ventilatory support on day 6 .

Of note, the chest radiograph on admission (Fig. 1) was normal. A series of chest radiographs from days 5 to 9 (Figs 2 - 5) showed progression of the lung injury from confluent infiltrates to a spontaneous right pneumothorax. After 5 days in the ICU, on the 11th day after the initial admission, the patient died of multiple organ failure including kidney, liver and respiratory failure (Table 1). During his stay in the ICU he was treated with antibiotics and furosemide.

\section{Discussion}

Paraquat (known in chemistry as $1,1^{\prime}$-dimethyl-4,4'-bipyridinium dichloride) is a herbicide that has been in the international market

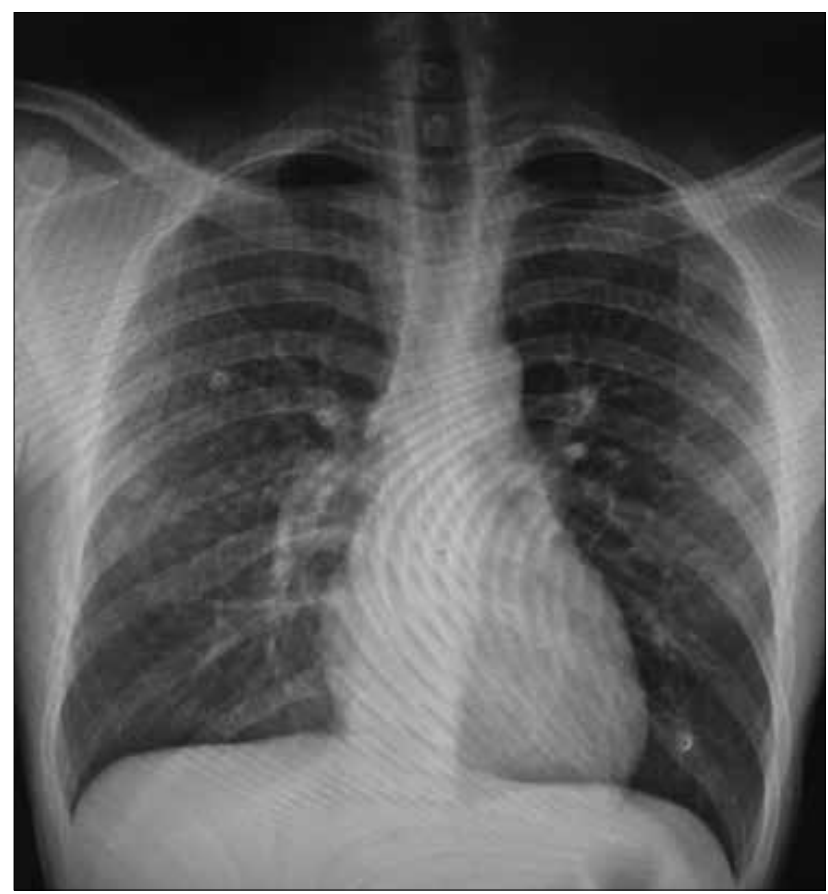

Fig. 1. Chest radiograph on day 0 (admission). The lung fields are clear and no pathology is detectable. 


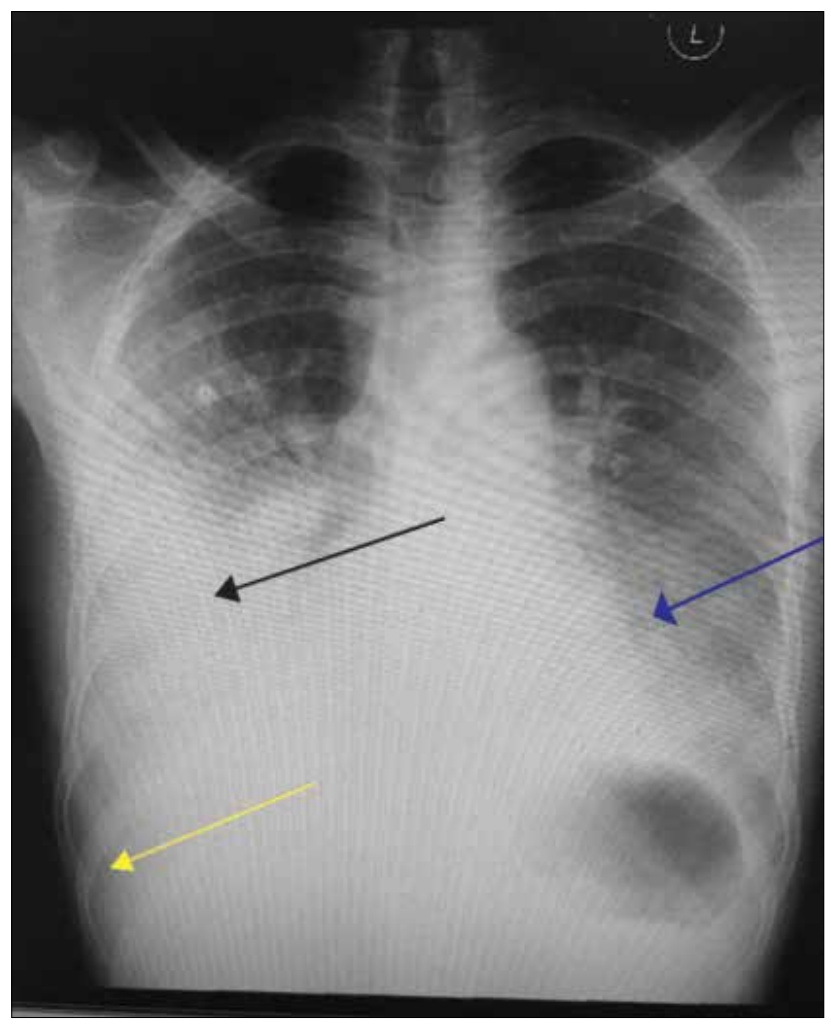

Fig. 2. Chest radiograph on day 5, showing homogeneous opacification of the right middle and lower zones (black arrow). The costophrenic angle is not visualised (yellow arrow). In the left lower zone, there is a fine reticulonodular appearance (blue arrow).

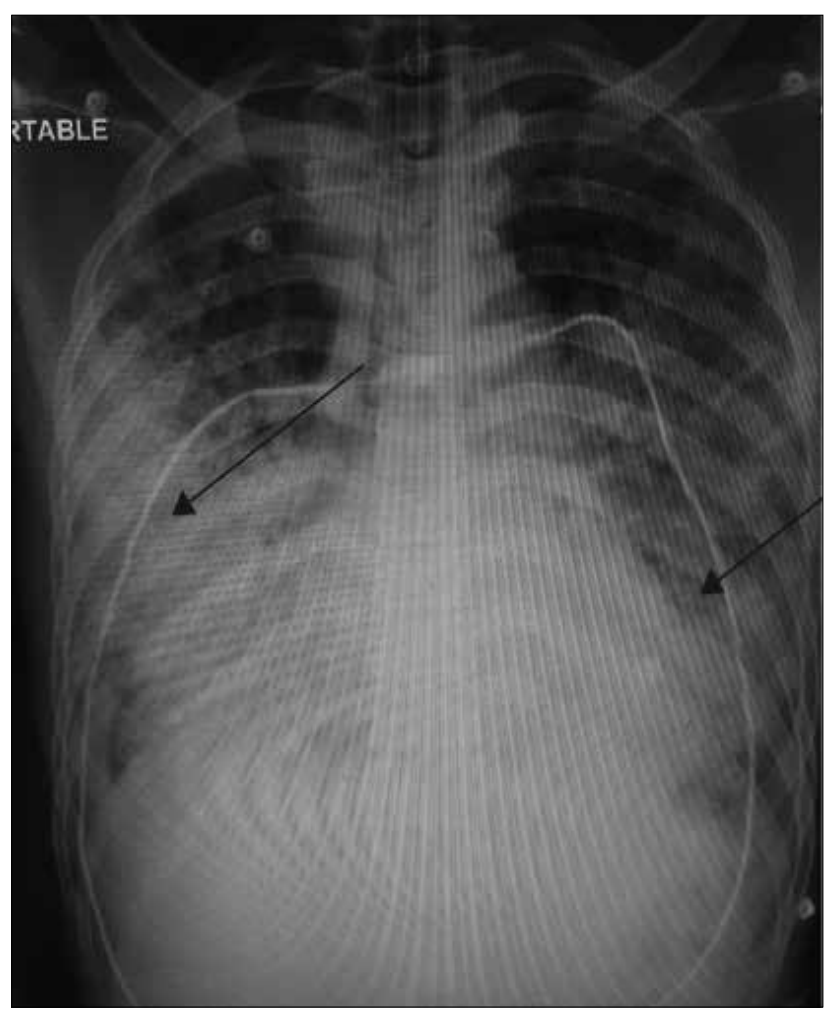

Fig. 3. Chest radiograph on day 6 , showing worsening of the lung opacification bilaterally, with predominance of a nodular pattern sparing the upper zones (black arrows). At this stage, the patient was intubated and having cardiac monitoring.

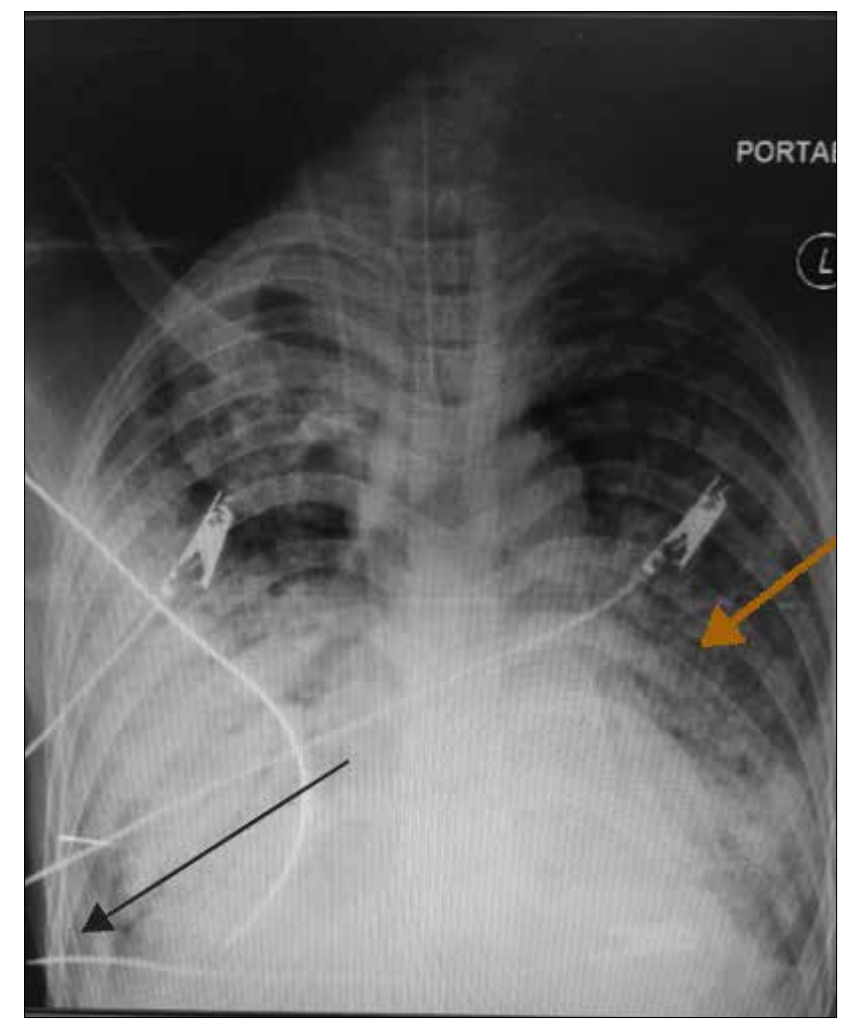

Fig. 4. Chest radiograph on day 7. Worsening of the nodular opacification of both lungs is evident, with visible air bronchograms (orange arrow), and a suggestion of an initial pneumothorax in the right lower zone (black arrow).

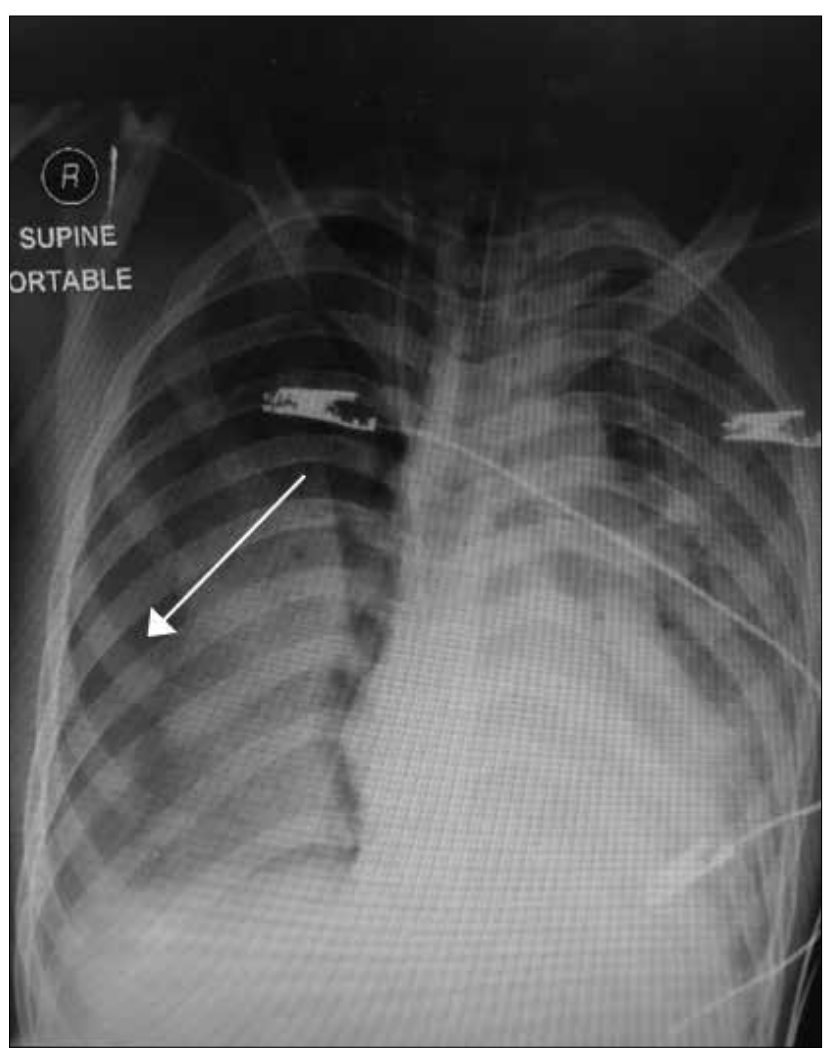

Fig. 5. Chest radiograph on day 9. Pneumothorax occupying the right hemithorax (white arrow) is evident, and a slight mediastinal shift towards the left suggests a tension pneumothorax. 
Table 1. Blood results

\begin{tabular}{|c|c|c|c|}
\hline Parameter & Admission (day 0) & ICU transfer (day 6) & Death (day 11) \\
\hline White cells $\left(\times 10^{9} / \mathrm{L}\right)$ & 10.19 & 14.36 & 16.89 \\
\hline Haemoglobin (g/dL) & 12.6 & 12.1 & 11.9 \\
\hline Platelets $\left(\times 10^{9} / \mathrm{L}\right)$ & 237 & 85 & 102 \\
\hline INR & 1.03 & 1.29 & 1.89 \\
\hline Urea $(\mathrm{mmol} / \mathrm{L})$ & 4 & 26.2 & 42.5 \\
\hline Creatinine $(\mathrm{mmol} / \mathrm{L})$ & 94 & 951 & 1031 \\
\hline $\operatorname{ALT}(\mathrm{U} / \mathrm{L})$ & 41 & 262 & 687 \\
\hline Bilirubin (umol/L) & 8 & 157 & 254 \\
\hline $\mathrm{pH}$ & & 7.17 & 7.06 \\
\hline $\mathrm{PO}_{2}(\mathrm{KPa})$ & & 5.1 & 7.8 \\
\hline $\mathrm{PCO}_{2}(\mathrm{KPa})$ & & 5.7 & 6.1 \\
\hline $\mathrm{HCO}_{3}(\mathrm{mmol} / \mathrm{L})$ & & 14 & 11 \\
\hline Oxygen saturation (\%) & $98 \%$ on $21 \% \mathrm{FiO}_{2}$ & $55 \%$ on $100 \% \mathrm{FiO}_{2}$ & $45 \%$ on $100 \% \mathrm{FiO}_{2}$ \\
\hline
\end{tabular}

since 1958. It has been shown to have toxic effects on the lungs, liver and kidneys in humans and livestock when inhaled or orally ingested (accidentally or intentionally), and is associated with high mortality. ${ }^{[2-4]}$ Since the 1970 s, death of patients with paraquat poisoning has been identified as mainly associated with acute lung injury. ${ }^{[5]}$

The pathophysiology of paraquat-induced acute lung injury resulting in spontaneous pneumothorax was first described by Daisley and Barton ${ }^{[6]}$ in 1990, after a report by Nakaoka et al. in 1987 of a spontaneous pneumothorax that occurred 7 years after paraquat ingestion (cited by Daisley and Barton ${ }^{[6]}$ ). Daisley and Barton ${ }^{[6]}$ discussed proposed mechanisms for the development of spontaneous pneumothorax in the setting of acute paraquat ingestion, including the deleterious effects of oxygen supplementation.

Im et al. ${ }^{[7]}$ described the findings on chest radiographs and computed tomography after paraquat poisoning, emphasising the sequential abnormalities that are visible on radiographs and their clinical implications. They identified a pattern of diffuse consolidation to be the most common early finding, which may appear in the first 7 days after ingestion. These changes evolved into a small cystic linear pattern up to about 15 days after ingestion, and a few weeks later patients who survived the acute event were found to have interstitial pulmonary fibrosis with decreased lung capacity.

In the same study, ${ }^{[7]}$ patients who developed pneumomediastinum within 7 days all died. Some of these patients had pneumothoraces. The mortality rate for patients who had used paraquat in a suicide attempt was $96 \%(26 / 27)$, while that after accidental ingestion was $40 \%(6 / 15)$. The overall mortality rate was $76 \%(32 / 42)$. Patients in the suicide group who died did so from 1 to 51 days after ingestion (mean 8.0), while those in the accidental ingestion group who died did so after 8 - 17 days (mean 11). ${ }^{[7]}$

The combination of early identification of the culprit substance, avoidance of oxygen supplementation, and early administration of immunosuppressive therapy such as cyclophosphamide, methylprednisolone and dexamethasone has been described as associated with good outcomes. ${ }^{[8]}$

\section{Learning points}

- In rural areas such as northern KwaZulu-Natal, where our patient was from, paraquat ingestion should be included in the differential diagnosis when dealing with patients with a history of ingesting an unknown substance. A high index of suspicion is the key to making the early diagnosis of paraquat-induced acute lung injury in patients with respiratory failure who have ingested an unknown substance.

- The classic radiological progression in paraquat poisoning is helpful, as diagnosis may be delayed without positive identification of the culprit substance (e.g. by obtaining the container), as happened in our case.

- Avoiding oxygen supplementation, and early administration of immunosuppressive therapy, can improve outcome.

Acknowledgements. We thank Dr L Padayachee, of the ICU at Ngwelezana Hospital.

Author contributions. SDN: concept, literature review and writing of the article; TCM: identification of the case for publication, and revision of the manuscript.

Funding. None.

Conflicts of interest. None.

1. Daisley H, Hutchinson G. Paraquat poisoning. Lancet 1998;352(9137):1393-1394. http://dx.doi. org/10.1016/S0140-6736(05)60796-9

. Campbell S. Paraquat poisoning. Clin Toxicol 1968;1(3):245-249. http://dx.doi.org/10 3109/15563656808990576

3. Paraquat poisoning. Lancet 1971;2(7732):1018-1019. http://dx.doi.org/10.1016/S0140-6736(71)90332-1 4. Davies DS, Hawksworth GM, Bennett PN. Paraquat poisoning. In: European Society of Toxicology.
Clinical Toxicology: Proceedings of the meeting held at Edinburgh, June 1976. Amsterdam: Excerpta Clinical Toxicology:

5. Bismuth C, Garnier A, Baud FJ, et al. Paraquat poisoning: An overview of the current status. Drug Saf Bismuth C, Garnier A, Baud FJ, et al. Paraquat poisoning: An overview of

1990;5(4):243-251. http://dx.doi.org/10.2165/00002018-199005040-00002
6. Daisley H, Barton EN. Spontaneous pneumothorax in acute paraquat toxicity. West Indian Med J 1990;39(3): 180-185

7. Im JG, Lee KS, Han MC, Kim SJ, Kim IQ. Paraquat poisoning: Findings on chest radiography and CT of 42 patients. AJR Am J Roentgenol 1991;157(4):697-701. http://dx.doi.org/10.2214/ajr.157.4.1892020 8. Neves FF, Sousa RB, Pazin-Filho A, Cupo P, Elias J, Nogueira-Barbosa MH. Severe paraquat poisoning: Clinical and radiological findings in a survivor. J Bras Pneumol 2010;36(4):513-516. http://dx.doi. org/10.1590/\$1806-37132010000400019

Accepted 25 January 2017. 